\title{
КОМПЛЕКСНАЯ ОЦЕНКА ЭФФЕКТИВНОСТИ ПРОИЗВОДСТВА ЗЕРНА В СЕЛЬСКОХОЗЯЙСТВЕННЫХ ОРГАНИЗАЦИЯХ КАК КРИТЕРИЯ ИХ ИНВЕСТИЦИОННОЙ ПРИВЛЕКАТЕЛЬНОСТИ *
}

\author{
(c) 2020 Зюкин Данил Алексеевич \\ кандидат экономических наук \\ Курская Государственная сельскохозяйственная академия имени И.И. Иванова, Россия, Курск \\ E-mail: nightingale46@rambler.ru
}

В статье рассматривается проблема низкой инвестиционной привлекательности и слабой развитости маркетинговой оценки результатов возделывания зерна. Формирование комплексной оценки эффективности производства зерна, в основе которой лежат показатели использования земли, позволяет оценивать реальную инвестиционную привлекательность зернового хозяйства и защищать зернопроизводителей от необоснованно низкой стоимости поглощения более крупным бизнесом.

Ключевые слова: зернопродуктовый подкомплекс, зерновое хозяйство, производство зерна, Курская область, инвестиционная привлекательность, производственно-экономические показатели воздельвания зерновых культур, результативность, эффективность.

Низкая инвестиционная привлекательность является главным тормозом развития российской экономики. Зерновое хозяйство, учитывая его более высокую рискованность и сезонность производства, изначально находится в более невыгодных условиях в сравнении с целым рядом отраслей. При этом зерно можно уверенно назвать стратегическим товаром в силу его значимости в хлебофуражном обеспечении населения и высокого экспортного потенциала, в то время как сама отрасль является стабильно прибыльной. Тем не менее, переход к инвестиционноинновационной модели в зернопродуктовом подкомплексе пока осуществлен не был, а инновации носят эпизодический характер. Проблема дополняется разрушением системы селекции и семеноводства в период рыночных реформ, что значительно сужает производственный потенциал всей воспроизводственной цепочки подкомплекса. Основным элементом интенсификации производства зерна на данный момент является использование минеральных удобрений, в то время как внедрение прорывных технологий в возделывание зерна и выведение новых районированных сортов можно встретить только у ограниченного числа зернопроизводителей.

Нежелание рисковать внедрять новые технологии определяется многими факторами, среди которых, на наш взгляд, важно отметить низкую инвестиционную привлекательность производства зерна, которая является следствием, в том числе недостаточной информированности инвесторов и кредиторов о результатах и эффективности работы отдельного бизнес-субъекта. Отсюда формирование комплексной оценки результативности и эффективности является информационной основой для улучшения инвестиционных перспектив отрасли. Объемная по количеству показателей и временному периоду информация о результатах деятельности предприятий, которую желательно публиковать на походящей информационной платформе, как раз и создает в глазах инвесторов, партнеров, кредиторов или государственных институтов соответствующий профиль, определяющий перспективы для сотрудничества.

Предоставление более подробной аналитической информации, особенно в разделе эффективности использования земли, получает актуальность в виду наметившегося тренда укрупнения производства зерна, когда за достаточно короткий период времени с 2014-2018 гг. крупные хозяйства удвоили свою долю в структуре посевных площадей, которая достигла 60,3\%. Данные таблицы 1 показывают, на сколько динамичным оказалось укрупнение производства зерна в Курской области. Если в 2014 г. в собственности сельскохозяйственных организаций с площадью посевов свыше 20 тыс. га при-

* Статья подготовлена при финансовой поддержке РФФИ в рамках научного проекта № 18-310-00211 
Таблица 1. Динамика наращивания площади посевов зерновых и валовых сборов в крупных организациях Курской области в 2014 и 2018 гг.

\begin{tabular}{|c|c|c|c|c|c|c|}
\hline $\begin{array}{c}\text { Сельскохозяй- } \\
\text { ственные органи- } \\
\text { зации с пло- } \\
\begin{array}{c}\text { щадью посевов } \\
\text { зерновых }\end{array}\end{array}$ & $\begin{array}{c}\text { Посевы } \\
\text { зерновых } \\
\text { культур, га }\end{array}$ & $\begin{array}{c}\text { Валовой сбор } \\
\text { зерна, т }\end{array}$ & $\begin{array}{c}\text { Посевы } \\
\text { зерновых } \\
\text { культур, га }\end{array}$ & $\begin{array}{c}\text { Валовой сбор } \\
\text { зерна, т }\end{array}$ & $\begin{array}{c}\text { Посевы } \\
\text { зерновых } \\
\text { культур, га }\end{array}$ & $\begin{array}{c}\text { Валовой сбор } \\
\text { зерна, т }\end{array}$ \\
\hline Более 20 тыс. га & 73190 & 267254 & 314286 & 1471139 & 241096 & 1203885 \\
\hline от 10 до 20 тыс. га & 134034 & 610976 & 150331 & 831986 & 16297 & 221010 \\
\hline
\end{tabular}

Источник: рассчитано автором по данным комитета агропромышленного комплекса Курской области

ходилось 73 тыс. га, то через 4 года показатель увеличился на 241 тыс. га, т.е. почти в 3,5 раза. Соответственно такие изменения в распределении посевных площадей определили рост влияния крупных производителей зерна на локальном рынке, так как в их руках сконцентрировано теперь почти 1,5 млн. т зерна (таблица 1).

Такое поглощение в российских условиях далеко не всегда происходит по рыночным принципам, а экономическая обоснованность стоит не в приоритете. Результаты на практике как раз и показывают, что укрупнение не является экономически оправданным, так как в сложившихся финансово-экономических условиях очень крупный бизнес при сопоставимой эффективности продаж менее результативно использует посевные площади. Группа хозяйств с площадью посевов от 4 до 10 тыс. га имеет наилучшие производственно-экономические показатели в 2018 году, а в дальнейшем по мере укрупнение организаций показатели снижаются. Хотя такой ситуации в 2014 году не наблюдалось - именно крупный бизнес был самым эффективным производителем зерна (таблица 2). Более того, наши предшествующие исследования доказывают, что в условиях 2011-2013 гг. крупные хозяйства также добивались самых высоких производственноэкономических результатов [1,2].

Исходя из сложившихся на практике тенденций, укрупнение в среднем не приводит к более результативному использованию посевных площадей. При этом процессы поглощения и перераспределения земли аграрного назначения происходят весьма активно: ТОП-20 самых крупных по размеру посевов зерновых компаний Курской области их увеличили в большинстве случаев значительно. Исключением стали ООО «Кшеньагро» и ООО «Льговагроинвест», входящие в состав группы Разгуляй, которая в 2017 год была признана банкротом из-за долг перед «Русагро» в размере 2,5 млрд. рублей. Наиболее сильное приращение посевных пло-

Таблица 2. Влияние размеров посевной площади на эффективность производства зерна в сельхозорганизациях Курской области в 2014 и 2018 гг.

\begin{tabular}{|c|c|c|c|c|c|c|}
\hline \multirow{2}{*}{$\begin{array}{c}\text { Группы хо- } \\
\text { зяйств, посев- } \\
\text { ная площадь, } \\
\text { тыс. га }\end{array}$} & \multirow{2}{*}{$\begin{array}{c}\text { Число } \\
\text { хозяйств в } \\
\text { группе }\end{array}$} & \multicolumn{4}{|c|}{ Приходится в расчете на 1 га посевов зерновых культур: } & \multirow{2}{*}{$\begin{array}{c}\text { Рентабель- } \\
\text { ность продаж } \\
\text { \% }\end{array}$} \\
\hline & & $\begin{array}{c}\text { выручки, тыс. } \\
\text { руб. }\end{array}$ & $\begin{array}{c}\text { прибыли, тыс. } \\
\text { руб. }\end{array}$ & $\begin{array}{c}\text { затрат, тыс. } \\
\text { руб. }\end{array}$ & $\begin{array}{c}\text { урожайности, } \\
\text { ц }\end{array}$ & \\
\hline \multicolumn{7}{|c|}{2018 год } \\
\hline более 20 & 8 & 37,3 & 11,6 & 25,7 & 46,8 & 31,1 \\
\hline от 10 до 20 & 11 & 45,3 & 14,1 & 31,2 & 55,3 & 31,2 \\
\hline от 4 до 10 & 16 & 53,7 & 17,4 & 36,5 & 59,5 & 32,5 \\
\hline от 1 до 4 & 80 & 42,2 & 13,6 & 28,6 & 47,2 & 32,3 \\
\hline менее 1 & 75 & 31,2 & 8,4 & 22,9 & 37,3 & 26,9 \\
\hline в области & 190 & 41,7 & 13,1 & 28,6 & 49,6 & 31,5 \\
\hline \multicolumn{7}{|c|}{2014 год } \\
\hline более 10 & 12 & 28,4 & 10,1 & 17,8 & 45,1 & 35,5 \\
\hline от 4 до 10 & 26 & 32,5 & 6,8 & 20,7 & 45,0 & 20,9 \\
\hline от 1 до 4 & 100 & 25,0 & 6,5 & 17,4 & 43,3 & 26,2 \\
\hline менее 1 & 90 & 21,3 & 5,2 & 15,0 & 36,1 & 24,6 \\
\hline в области & 228 & 27,9 & 7,6 & 18,3 & 43,8 & 27,1 \\
\hline
\end{tabular}

Источник: рассчитано автором по данным комитета агропромышленного комплекса Курской области 
щадей в абсолютном выражении произошло в ООО «Пристенская зерновая компания» - на 30,3 тыс. га; в ООО «КурскАгроАктив» - на 26,6 тыс. га; ООО «Русский Ячмень» - на 13,5 тыс. га; ЗАО Касторное АГРО-Инвест - на 13,4 тыс. га; АО «Артель» - на 11,3 тыс. га, а еще в 7 сельскохозяйственных организациях прирост составил более 5 тыс. га.

Столь динамичные изменения прямым образом доказывают высокую инвестиционную привлекательность деятельности в сфере растениеводства в Курской области, в особенности, его основного направления - возделывания зерновых культур. Высокая конкурентоспособность других групп зерносеющих также только подчеркивает инвестиционную привлекательность это аграрного направления и мотив для дальнейшего перераспределения земель. Резервов неиспользуемых площадей в области практически нет, а площадь чистых паров уже минимизирована до 50 тыс. га, в сравнении с 290 тыс. га на начало реализации национального проекта в 2006 году. Конечно, такой подход несет в себе угрозы, в первую очередь, для экологии почв. Учитывая это вероятность дальнейшего поглощения крупных организаций более мелких только увеличивается, чему также способствует недооценность стоимости земли, если сопоставлять по ее относительной плодородности в сравнении с другими регионами России и странами мира.

Будучи многогранной характеристикой, инвестиционная привлекательность подвержена воздействию множества факторов, а комплексная оценка может включать широкий перечень показателей, в том числе специфических для отрасли. В производстве зерна к таковым следует отнести показатели, представляющих производственно-экономическую оценку возделывания зерновых культур, в основе которых находится оценка использование посевных площадей. Комплексная оценка того на сколько эффективно и результативно используется земля под сельскохозяйственное производство может давать более справедливую стоимостную оценку для хозяйств, занимающихся растениеводством. Стоимость земли при поглощении следует увязывать с результатами, которыми добивается сельхозтоваропроизводитель, чтобы защитить его при продаже от недооценки. Поэтому такая ситуация может стимулировать показать агропроизводителям реальные результаты деятель- ности, если будут инструменты защитить их собственность от необоснованно заниженной цены продажи. Также критерии более высокой результативности следует законодательно установить как обоснование считать сделку по поглощению нелегитимной, а государственные органы, отвечающие за это, подвергнуть проверки и административной ответственности, ведь в таких процессах крупным бизнесом часто используется административная поддержка.

Для экономики России важно обеспечить более эффективное задействование посевных площадей в производстве и получение прироста урожая зерновых, а поэтому поддержка более эффективных агропроизводителей оправдана. Однако крупный бизнес, пользуясь экономическим постулатом о своими априорно лучшими возможностями для достижения результатов производства и использования ресурсов, не всегда эффективнее будет использовать их. Согласно результатам таблицы 3 самые крупные сельскохозяйственные организации области, занимающиеся возделыванием зерновых культур, крайне дифференцированы по уровню производственно-экономических показателей.

Размах вариации урожайности составил от 35,6 до 77,7 ц/га, рентабельности продаж - от 4,3 до 56,3\%, выручки и прибыли от реализации зерна в расчете на 1 га посевов зерновых - от 25,1 до 61,4 тыс. рублей и 0,8 до 34,6 тыс. рублей, т.е. обстановка принципиально разная и предпосылки для наращивания посевов в дальнейшем соответственно также сильно отличаются по представленным сельскохозяйственным организациям. Размах вариации является абсолютным показателем, поэтому для характеристики однородности совокупности обычно используется коэффициент вариации. В нашем случае его значения свидетельствуют о высоком значении вариации для показателей выручки от реализации и затрат на производство в расчете на 1 га посевов зерновых культур и урожайности зерновых, при этом анализ рентабельности продаж и прибыли от реализации в расчете на 1 га посевов зерновых культур вообще говорит о неоднородности выборки. Коэффициент корреляции отражает слабую стохастическую связь производственно-экономических результатов и размера посевных площадей, к тому же выявлен обратный характер связи, т.е. все изучаемые показатели имеют тенденцию к снижению с укрупнением производства (таблица 4). 
Таблица 3. Производственно-экономические оценка возделывания зерновых культур в крупнейших сельскохозяйственных организациях Курской области в 2018 гг.

\begin{tabular}{|c|c|c|c|c|c|c|}
\hline \multirow{2}{*}{ Сельскохозяйственные организации } & \multirow{2}{*}{\begin{tabular}{|c|} 
Размер \\
посевов \\
зерновых, \\
га
\end{tabular}} & \multicolumn{4}{|c|}{$\begin{array}{c}\text { Приходится в расчете на } 1 \text { га посевов } \\
\text { зерновых культур: }\end{array}$} & \multirow{2}{*}{$\begin{array}{c}\text { Рента- } \\
\text { бельность } \\
\text { продаж,\% }\end{array}$} \\
\hline & & $\begin{array}{l}\text { выручки, } \\
\text { тыс. руб. }\end{array}$ & $\begin{array}{l}\text { прибыли, } \\
\text { тыс. руб. }\end{array}$ & $\begin{array}{l}\text { затрат, } \\
\text { тыс. руб. }\end{array}$ & $\begin{array}{l}\text { урожай- } \\
\text { ности, ц }\end{array}$ & \\
\hline ООО «Курск-Агро» & 82847 & 25,1 & 3,9 & 21,2 & 35,6 & 15,6 \\
\hline ООО «Авангард-Агро-Курск» & 51756 & 46,1 & 15,7 & 30,5 & 46,3 & 34,0 \\
\hline ООО «КурскАгроАктив» & 43315 & 18,3 & 3,7 & 14,5 & 40,1 & 20,5 \\
\hline ООО «Пристенская зерновая компания» & 39542 & 41,4 & 8,3 & 33,1 & 55,9 & 20,1 \\
\hline ООО «Русский Ячмень» & 25120 & 59,7 & 19,5 & 40,4 & 76,6 & 32,7 \\
\hline ООО «АПК-Черноземье» & 24791 & 61,4 & 34,6 & 26,9 & 57,5 & 56,3 \\
\hline ООО «Агрокомплекс Олымский» & 23789 & 39,8 & 14,8 & 25,0 & 41,4 & 37,1 \\
\hline ЗАО Касторное АГРО-Инвест & 23126 & 37,2 & 14,1 & 23,1 & 47,0 & 37,9 \\
\hline АО «Артель» & 17569 & 49,6 & 17,6 & 32,1 & 77,7 & 35,4 \\
\hline ЗАО АФ»Рыльская» & 16002 & 57,9 & 26,9 & 31,1 & 54,9 & 46,4 \\
\hline ООО «Агросил» & 15194 & 59,7 & 22,8 & 37,1 & 67,7 & 38,2 \\
\hline ЗАО Дмитриев-АГРО-Инвест & 14537 & 35,4 & 2,3 & 33,1 & 64,3 & 6,4 \\
\hline ООО «Агрокомплекс «Глушковский» & 14402 & 47,9 & 14,7 & 33,7 & 52,4 & 30,8 \\
\hline ООО «Агрокультура Курск» & 14124 & 18,5 & 0,8 & 17,7 & 30,6 & 4,3 \\
\hline ООО «Кшеньагро» & 13525 & 40,3 & 20,3 & 20,0 & 46,0 & 50,4 \\
\hline АО «Щигровская МТС» & 12823 & 42,3 & 7,4 & 34,9 & 67,2 & 17,5 \\
\hline ООО «Конек Горбунок» & 11523 & 50,1 & 8,5 & 41,6 & 56,6 & 17,0 \\
\hline ООО «Защитное» & 10596 & 52,7 & 12,6 & 40,1 & 39,3 & 23,9 \\
\hline ООО «Льговагроинвест» & 10036 & 41,6 & 18,4 & 23,2 & 37,6 & 44,2 \\
\hline
\end{tabular}

Источник: рассчитано автором по данным комитета агропромышленного комплекса Курской области

Таблица 4. Статистическая оценка взаимосвязи размеров посевных площадей и производственноэкономических показателей возделывания зерновых культур в Курской области в 2018 гг.

\begin{tabular}{|c|c|c|c|c|c|}
\hline \multirow{2}{*}{ Показатель } & \multicolumn{4}{|c|}{$\begin{array}{c}\text { Приходится в расчете на } 1 \text { га посевов зерновых } \\
\text { культур: }\end{array}$} & \multirow{2}{*}{$\begin{array}{c}\text { Рента- } \\
\text { бельность } \\
\text { продаж,\% }\end{array}$} \\
\hline & $\begin{array}{l}\text { выручки, } \\
\text { тыс. руб. }\end{array}$ & $\begin{array}{l}\text { прибыли, } \\
\text { тыс. руб. }\end{array}$ & $\begin{array}{l}\text { затрат, тыс. } \\
\text { руб. }\end{array}$ & $\begin{array}{l}\text { урожайно- } \\
\text { сти, ц }\end{array}$ & \\
\hline Размах вариации, в абсолютных единицах & 43,1 & 33,8 & 27,1 & 47,1 & 52,0 \\
\hline Коэффициент вариации,\% & 28,9 & 61,1 & 26,4 & 25,6 & 47,2 \\
\hline Коэффициент корреляции & $-0,38$ & $-0,26$ & $-0,34$ & $-0,28$ & $-0,18$ \\
\hline
\end{tabular}

Источник: рассчитано автором по данным комитета агропромышленного комплекса Курской области

Тем самым еще раз доказывается, что путь укрупнения производства в зерновом хозяйстве далеко не идеален, а не редко приводит к снижению производственно-экономических результатов и инвестиционной привлекательности предприятия. $\mathrm{K}$ тому же такое резкое изменение структуры рынка продавцов негативно действует на условия работы локального зернового рынка, формируя там диспропорции и неблагоприятную ценовую конъюнктуру.

Это показывает, что дальнейшее перераспределение земли от малых хозяйств к крупным в рамках политики укрупнения производства требует более объективной оценки, так как результатом может стать не просто снижение общих показателей зернового хозяйства, но и создание условий, негативно влияющих на инвестиционную привлекательность и бизнес среду в сельском хозяйстве области. Комплексная оценка того как используется земля под сельскохозяйственное производство может являться маркером таких сомнительных сделок. Заинтересованность в этом есть у всех участников рынка и государства. С одной стороны, бизнес-субъекты, 
показывая свою инвестиционную привлекательность, в какой-то степени лучше защищают себя от поглощения, с другой стороны, бизнессубъекты, которые желают укрупняться и активнее быть на рынке, должны показывать экономическую обоснованность для таких действия.

Государство заинтересовано в более высоких производственно-экономических показателях, за счет которых будет, в том числе получено больше налоговых отчислений. Напрямую вмешиваться в частные отношения государство не может, если оно не носит противоправных действий. Поэтому важно совершенствовать механизм контроля за сделками, в результате которых земли сельскохозяйственного назначения приобретаются по ценам существенно ниже рыночных, на которые одна из сторон соглашается под давлением, в том числе административному. Регулирование перераспределения земельных ресурсов необходимо осуществлять на рыночных принципах, обеспечивающих их более эффективное и природосберегающее использование, а также формирующих благоприятный инвестиционный фон в отрасли. В случае, если поглощение будет происходить бесконтрольно и при отсутствии экономической целесообразности это ударит по перспективам развития зернового хозяйства, так как бизнес не будет заинтересован осуществлять вложения под реализацию инновационно-инвестиционных проектов и программ, когда его могут поглотить да еще и не на рыночных, экономически несправедливых условиях.

\section{Библиографический список}

1. Зюкин Д.А. Учет эффекта масштаба при совершенствовании стратегии развития зернового хозяйства // АПК: экономика, управление. 2018. № 12. С. 52-58.

2. Зюкин Д.А. Повышение эффективности использования и распределения средств государственной поддержки, направленных на развитие зернового хозяйства: Монография. Курск: «Деловая полиграфия»,2012.- 120 c. 